\title{
The Influence of Parenting Styles and Self-concept on the Academic-achievement of Moslem Adolescent in South Jakarta
}

\author{
Danial Thaib ${ }^{1}$, Silvana Syah ${ }^{2}$ \\ \{danialthaib@ibi-k57.ac.id ${ }^{1}$, silvanasyah@ibi-k57.ac.id $\left.{ }^{2}\right\}$
}

${ }^{1,2}$ Fakultas Ekonomi, Manajemen Institut Bisnis dan Informatika Kosgoro 1957, Jakarta Indonesia

\begin{abstract}
This paper examines the relationship between parenting styles and selfconcept with academic-achievement of moslem adolescent. Data were collected from 160 adolescents of both gender in Southern Jakarta. Authoritative, authoritarian and permissive are types of parenting styles. The two types of self-concepts are positive selfconcept and negative self-concept. Academic-achievement has been designed by the researcher based on The Quran and Hadith subject. The analysis examines that most of the respondents' parents practised authoritative parenting-style and also most of the respondents have negative self-concept. Analyses of variance were computed on the scores obtained from the self-report instrument administered and correlations between these scores and achievement scores were calculated. The correlation presents that there is significant relationship parenting style and self concept on academic achievement.
\end{abstract}

Keyword: parenting styles, self-concept, academic-achievement.

\section{Introduction}

The research is motivated by the theory and understanding of thinking that parenting parents and self-concept can improve academic-achievement considering these factors are the result of a long policy review. But in reality on the ground, sometimes distortions occur from these expectations.

Parenting is the process of promoting and supporting the physical, emotional, social financial and intellectual development of a child from infancy to adulthood.[1] The meaning is that parenting is an interaction between parents and children in meeting physical and psychological needs as well as educating, teaching and socializing the values and norms prevailing in society so that children can adjust to the environment in which they live. Parenting activities carried out by educating, guide, provide protection, and supervision of children. Individual experiences and opinions make a difference in the adoption of parenting to child. Baumrind views the parenting-style from a combination of four characteristics, namely warmth (n Regularce), expectations of expectations which are described in the context of maturity demands, clarity and consistency of parental rules, communication between parents and children. From these four combinations, three types of parenting are explained, namely: (1) Authoritarian parenting; that is parenting which is characterized by strict control and demands for maturity, but low in nuturance and communication. (2) Permissive parenting, namely parenting that is characterized by high nuturance, but low in the demands of maturity, 
(3) authoritative parenting, namely parenting that is characterized by nuturance, demands for maturity, control always support, give gifts and praise children as well as communication between parents and good children.[2]

Children need support and attention from the family in creating their work. Therefore, parenting that is considered more suitable to help children develop their creativity is authoritative or commonly known as authoritative. In this parenting, parents give control to their children within certain limits, rules for essential things, while still showing support, love and warmth to their children. Through this parenting the child can also feel free to express his difficulties, anxiety to parents because he knows, parents will help him find a way out without trying to dictate it.

Research has found that parenting-style is significantly related to a child's subsequent mental health and well-being. In particular, authoritative parenting is positively related to mental health and satisfaction with life, and authoritarian parenting is negatively related to these variables.[3]

The self-concept as a foundation in achieving success in life. The self-concept as a determinant of direction in acting. Students with positive self-concepts tend to act more positively in learning, the task of the teacher will be completed with full responsibility and learning obstacles he makes as a challenge and able to enthusiasm for learning. Self-concept also differs from self-esteem: self-concept is a cognitive or descriptive component of one's self (e.g. "I am a fast runner"), while self-esteem is evaluative and opinionated (e.g. "I feel good about being a fast runner"). The concept of self consists of five components, namely: selfideal, self-esteem, image body, identity, and role. Self-concept of children aged 10-12 years develop in line with the characteristics that occur where the five components these will support each other. Experience gained and perspective in response to the development of characteristics will be different for each individual. This will make the self-concept of children aged 10-12 years one different to each other.[4]

\section{Objectives}

To study the influence of parenting style and self concept on academic achievement of moslem adolescent in South Jakarta.

\section{Methodology}

\subsection{Research design}

This type of research based on the approach is research quantitative. Quantitative research is closely related with social survey techniques including structured interviews and structured questionnaires, experiments, structured observations, content analysis, formal statistical analysis and much more.

\subsection{Sample and population}

The simple random sampling method was chosen. The total sample for the study comprised of 160 moslem adolescent in South Jakarta. 


\section{Findings}

\subsection{Parenting-style}

The analysis of the data indicated academic-achievement of respondents was the authoritative style is high (average=75.25) followed by the authoritarian style (average $=72.27$ ) and permissive (average $=70.30)$.

\subsection{Self-concept}

The analysis of the data indicated that students' level of positive self-concept is high (average $=73.97$ ) and a significant relationship exists between self-concept and academic achievement. This followed by negative self-concept (average=71.24)

\subsection{Correlation Between Parenting-style and the adolescents' academic-achievement}

We ran anova analysis to tests of Between-Subjects Effects. There is correlation between parenting-style and the adolescent academic-achievement. $(\mathrm{p}=0.01<\alpha=0.05)$. The authoritative parenting styles can show higher academic performance, followed by authoritarian and permissive parenting styles.

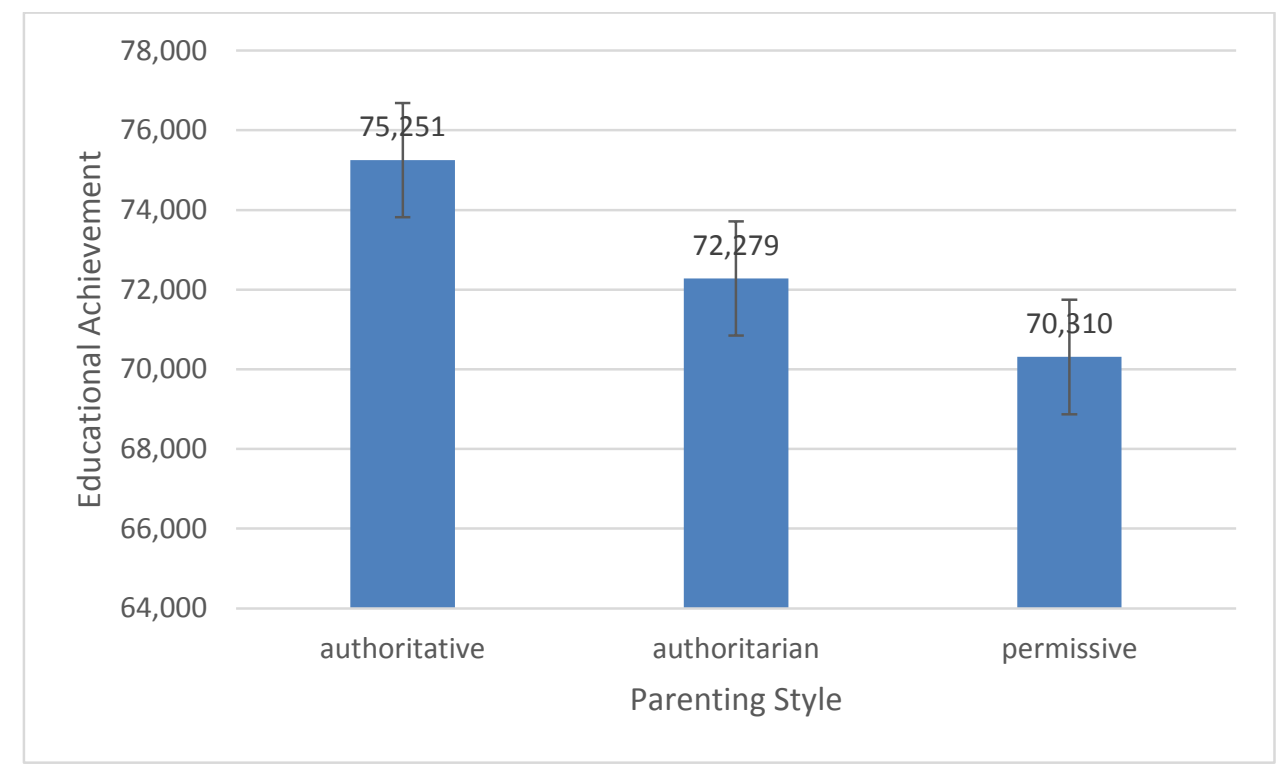

Fig. 1.

\subsection{Correlation Between Self-concept and the adolescents' academic-achievement}

To explore the relationship between self concept and the adolescents' academicachievement, we ran anova analysis to tests of Between-Subjects Effects. There is correlation between self concept and the adolescent academic-achievement. $(p=0.08<\alpha=0.05)$. The positive self-concept can show higher academic performance than the negative. 


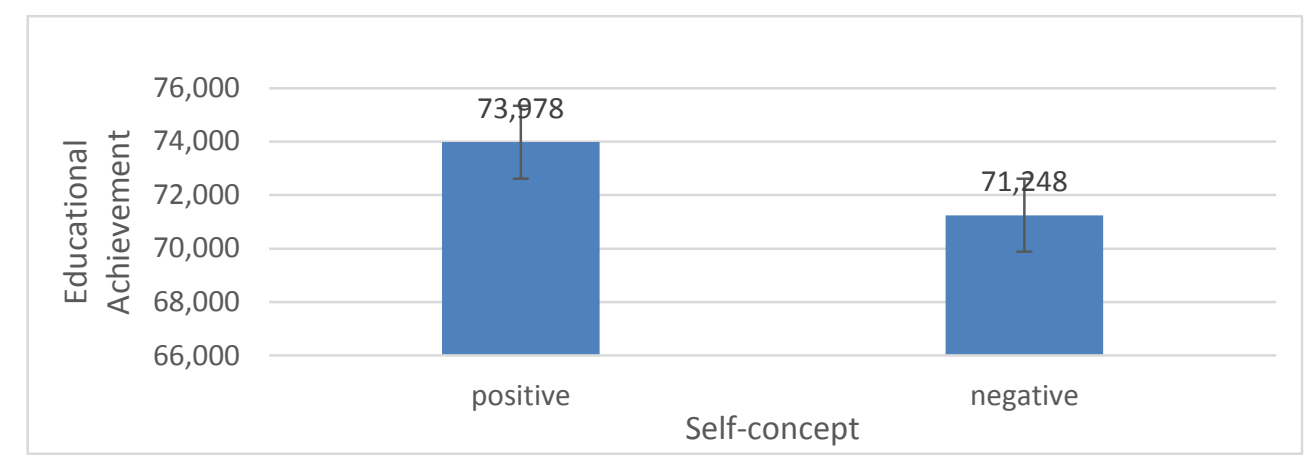

\section{Discussion}

The results show that authoritative and positive self-concept are significant predictors for higher academic-achievement. Authoritative parenting is a way of educating children, where parents determine the rules but with regard to the circumstances and needs of children. Authoritative parenting is a form of parenting that pays attention to and respects the freedom of children, but that freedom is not absolute and with understanding guidance between parents and children. In other words, this authoritative parenting gives children freedom to express opinions, do what they want by not crossing the boundaries or rules set by parents. Parents also always provide guidance and direction with full understanding of what children can do and what cannot. This is done by parents gently and lovingly.

The pattern of fostering authoritative is characterized by an open attitude between parents and children. They make rules that are mutually agreed upon. Children are given the freedom to express their opinions, feelings and desires. So in this parenting there is good communication between parents and children.

Authoritative parenting can be said to be a combination of two extreme contradictory parenting, namely authoritarian parenting and permisive. The pattern of authoritative care is characterized by an open attitude between parents and children. They make rules that are mutually agreed upon. Children are given the freedom to express their opinions, feelings and desires and learn to be able to respond to the opinions of others. Parents act as givers of opinion and consideration of children's activities. With this pattern of care, children will be able to develop control of their own behavior with things that are acceptable to the community. This encourages children to be able to stand alone, responsible and confident about themselves. Her creativity developed well because parents always stimulated their children to be able to take the initiative

\section{Reference}

[1] S. Mahapatra and R. Batul, "Psychosocial Consequences of Parenting," IOSR J. Humanit. Soc. Sci. (IOSR-JHSS, vol. 21, no. 2, pp. 10-17, 2016.

[2] F. B. Farzana Bibi, "Contribution of Parenting-style in life domain of Children," IOSR J. Humanit. Soc. Sci., vol. 12, no. 2, pp. 91-95, 2013. 
[3] C. Y. Huang et al., "Relationships between parent-reported parenting, child-perceived parenting, and children's mental health in Taiwanese children," Int. J. Environ. Res. Public Health, vol. 16, no. 6, 2019.

[4] G.-S. Jeon, "A Study on the Happiness Factors of Adolescents," Korean J. Youth Stud., vol. 23, no. 10, p. 411, 2016. 